International Journal on Intelligent Electronic Systems, Vol. 5, No.1, January 2011

\title{
EMBEDDED CONTROLLED ZVS DC-DC CONVERTER FOR ELECTROLYZER APPLICATION
}

\author{
Samuel Rajesh Babu R. ${ }^{1}$, Henry Joseph ${ }^{2}$ \\ ${ }^{1}$ Research Scholar, Sathyabama University, Chennai, India. \\ ${ }^{2}$ Vel Tech University, Chennai, India. \\ Email: ${ }^{1}$ samuel.rajeshbabu@gmail.com
}

\section{Abstract}

An Electrolyser is part of a renewable energy system (RES) and generates hydrogen from water electrolysis that is used in fuel cells. A static DC-DC converter is required to couple the Electrolyser to the system DC bus. This paper presents the design of three soft-switched high-frequency transformer isolated DC-DC converters for this application based on the given specifications. It is shown that LCL- type series resonant converter with capacitive output filter is suitable for this application. Detailed theoretical and simulation results are presented. Due to the wide variation in input voltage and load current, no converter can maintain zero-voltage switching for the complete operating range. The experimental results are compared with the simulation results and they are almost similar.

\section{INTRODUCTION}

A renewable energy system (RES) converts the energy found in sunlight, wind, falling water, waves , geothermal heat, or biomass into a useable form, such as heat or electricity, A typical RES that is under development at the Institute for Integrated Energy Systems (IES Vic) laboratory, University of Victoria is shown in Fig. 1, Renewable energy storage in the form of hydrogen may overcome the inherent weakness of battery based energy storage systems like physical size, limited life span, initial capital cost of the battery bank coupled with transportation, maintenance, and battery disposal issues.

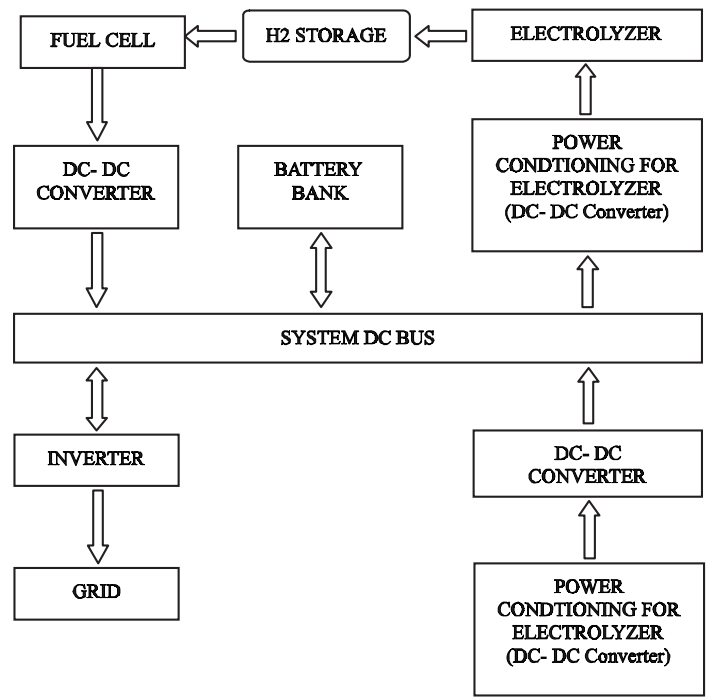

Fig. 1 Block Diagram of a typical Renewable Energy System
During periods when the renewable resources exceed the load demand, hydrogen would be generated and stored through water electrolysis. For this purpose Electrolyser, which breaks water in to hydrogen and oxygen is used as an integral part of RES in Fig. 1. During periods when the load demand exceeds the renewable resource input, a fuel cell operating on the stored hydrogen would provide the balance of power.

To ensure proper flow of power between the systems elements, the available energy form different sources are coupled to a low voltage DC bus. A direct connection of DC bus to the Electrolyser is not suitable because it lacks the ability to control the power flow between the renewable input source and the Electrolyser. Therefore, a power conditioning system, usually a DC-DC converter is required to couple the Electrolyser to the system bus.

\section{SPECIFICATIONS AND POSSIBLE CONVERTER CONCIGURATIONS}

The major specifications of the dc-to-dc converter for the present application are: Maximum output power=7.2 kw; input DC voltage $=40 \mathrm{~V}$ to $60 \mathrm{~V}$ : output Dc Voltage $=40 \mathrm{~V}$ to $60 \mathrm{~V}$; output current range $=40$ $\mathrm{A}$ at $60 \mathrm{~V}$ and linearly derated to $10 \mathrm{~A}$ at $40 \mathrm{~V}$; output voltage ripple $=100 \mathrm{mV}$; electrical isolation between input and output.

High Bfrequency (HF) transformer isolated, HF switching dc-to-dc converters are suitable for this application due to their small size. Light weight and reduced cost. To increase their efficiency and to further 
increase the switching frequency wile reducing the size, cost and EMI problems soft-switching techniques (1-12) will be used in this paper, Due to the high power requirement, an interleaved, Multi-cell configuration (13-14) that uses 3-cells (each rated at $2.4 \mathrm{~kW}$ ) in parallel (both at the input and output) with each cell being phase shifted by $120(=360 / 3)$ is adopted. Each cell shares equal power and the thermal losses are distributed uniformly among the cells. Also, the input/output ripple is three times the switching frequency.

There are three major types of HF transformer isolated soft- switching convertor configurations possible: (a) Voltage fed resonant converters (1-8) ; (b) current fed resonant converters (1); and (c) fixed B frequency resonant transition zero-voltage switching (ZVS) PWM bridge converter (6-12) Our studies show that current fed resonant converters require HF switches rated at 5 to 6 times the input voltage (reducing the efficiency) in the present application and therefore they are not considered further. Voltage fed resonant converters can be operated either in variable frequency mode or fixed frequency mode. But the operation in variable frequency mode suffers form several disadvantages: wide variation in switching frequency making the design of filters and control circuit difficult. Therefore, fixed frequency operation is adopted in this paper.

From the above discussions, we are left with mainly the following six soft-switching converter configurations for the Electrolyer application.

1. Fixed B frequency series resonant converter (SRC) (3)

2. Fixed Bfrequency paralled resonant converter (PRC) (4)

3. Fixed B frequency series-parallel or LCC B Type resonant converter (SPRC) (5)

4. Fixed $B$ frequency $L C L$ series resonant converter (SRC) with a capacitive output filter $(6,7)$

5. Fixed $B$ frequency $L C L$ SRC with an inductive output filter (8)

6. Fixed Bfrequency phase-shifted ZVS PWM full B bridge converter (9-11)

Among the above six converter configurations, the SRC and SPRC can operate with the ZVS, only for very narrow variations in supply and load variations in the present applications. In the case of PRC, the inerter peak current does not decrease much with reduction in the load current and there is no coupling capacitor in series with the HF transformer. Therefore, the first three configurations are not considered for further study and we will study only the latter three configurations. The literature [1] to [10] does not present the closed loop simulink mode for ZVS DC to DC converter, the objective of the paper is present simulation and implementation of closed loop controlled ZVS DC to DC converter.

\section{DESIGN AND COMPARISON OF SELECTED CONVERTERS}

The selected converters are designed for the worst operating conditions of: minimum input voltage, $\mathrm{V}$ in $=40 \mathrm{~V}$; maximum out put voltage, $\mathrm{V} 0=60 \mathrm{~V}$; and maximum output power (2.4 kW for each cell); switching frequency, $f \mathrm{~s}=100 \mathrm{kHz}$; inverter output pulse-width, ä =

\section{A. Fixed-Frequency LCL SRC with Capacitive Output Filter:-}

The basic circuit diagram of the modified series (LCL-type) resonant converter with capacitive output filter and its typical operating waveforms for fixed B frequency operation using phase-shifted gating signals. This converter has been analyzed using the Fourier series approach (6) and approximate analysis (7) it has been shown that the converter operates in lagging PF mode for a very wide change in load and the primary switches. The Peak current through the switches decreases with load current. The converter is designed based on the analysis and design procedure given in (6) the following values is found to be a near optimum for the design specifications. Resonant inductance ratio, $\mathrm{L}_{\mathrm{r}} / \mathrm{L}_{\mathrm{t}}==0.1$; normalized load current,

$\mathrm{J}=0.427$, Converter gain, $\mathrm{M}=0.965$; normalized switching frequency, $F=1.1$; where $L_{t}==\left(n_{t}^{2}\right) L_{t}, J=\left(l_{d} /\right.$ $\left.n_{t}\right) / I_{B}, I_{B}=V_{\text {in }} / Z, Z=\left(L_{r} / C s\right)^{2} M=\left(n_{1} V_{0}\right) / N i n, F=u_{s}$ $/ \grave{u}_{r}, \grave{u}_{s}=2 f_{s}, \grave{u}_{r}=1 /\left(L_{r} C_{s}\right)^{1 / 2}, f_{s}=$ Switching frequency.

\section{DC-DC CONVERTER}

DC-DC Converter for Electrolyser application is shown below. DC is converted into high frequency $A C$ using an inverter. The high frequency $A C$ is stepped down and it is rectified using a rectifier. The DC output of the rectifier is used to feed the electrolyser plant. 
This converter has advantages like reduced transformer and filter size.

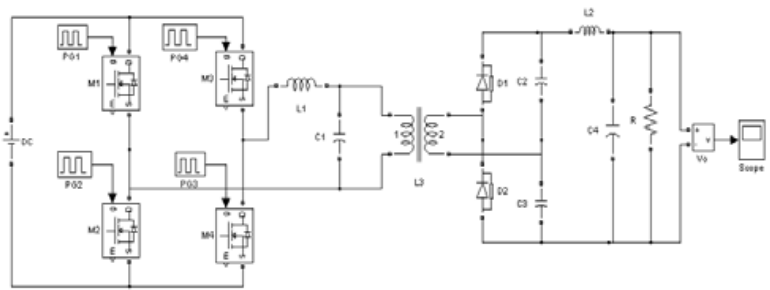

Fig 2a DC to DC Converter

\section{SIMULATION RESULTS}

The simulation is done using matlab simulink and the results are presented. The simulation circuit is shown in Fig. 2a. Driving pulses for M1 and M2 are shown in Fig. 2b. The resonant inverter output is shown in Fig 2c. DC output voltage and current are shown in Fig. 2d. Variation of output with the input voltage is shown in Fig. 2e. Variation of output voltage with load is shown in Fig. $2 f$.

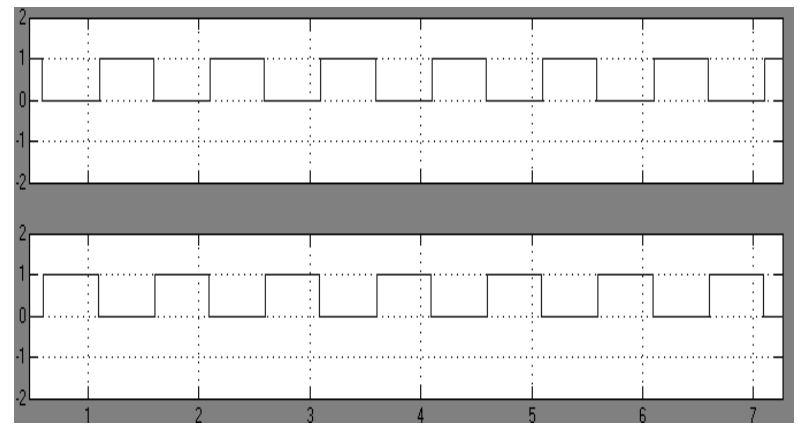

Fig $2 b$ - Driving Pulse for M1 and M2
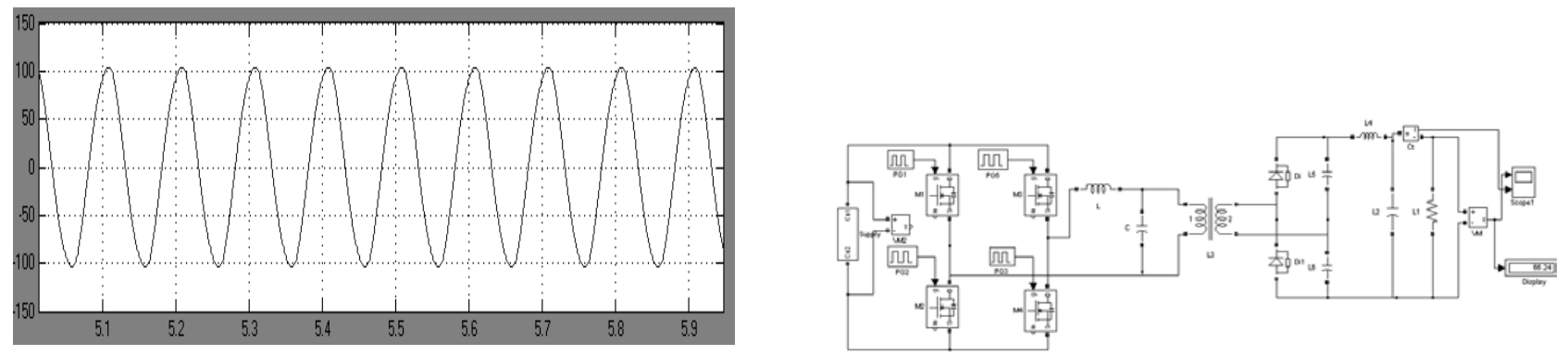

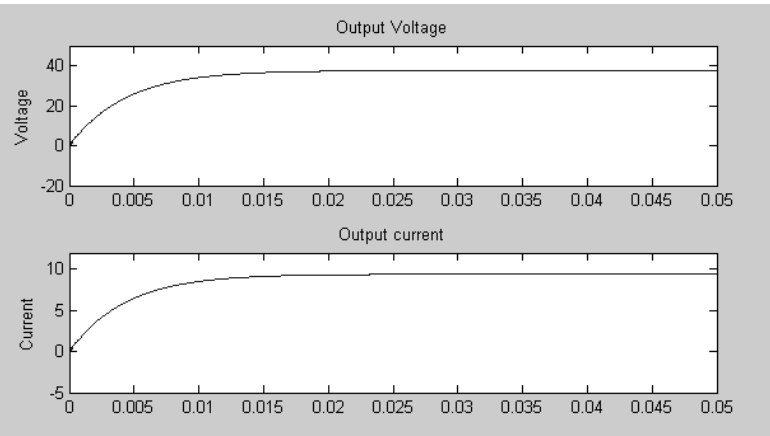

Fig 2d - Output Voltage and Current Waveforms

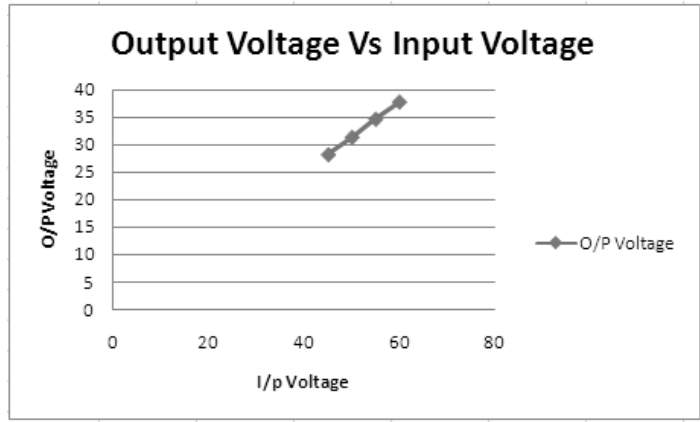

Fig 2e - Output Voltage Vs Input Voltage

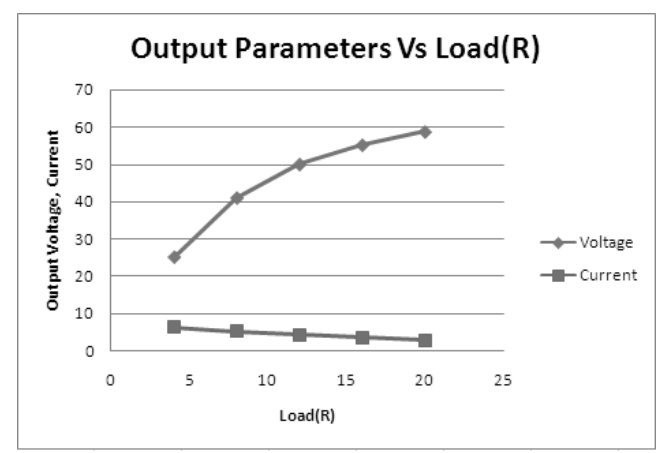

Fig $2 f$ Output Parameters Vs Load 7

Fig 2c - Resonant Inverter Output Voltage 


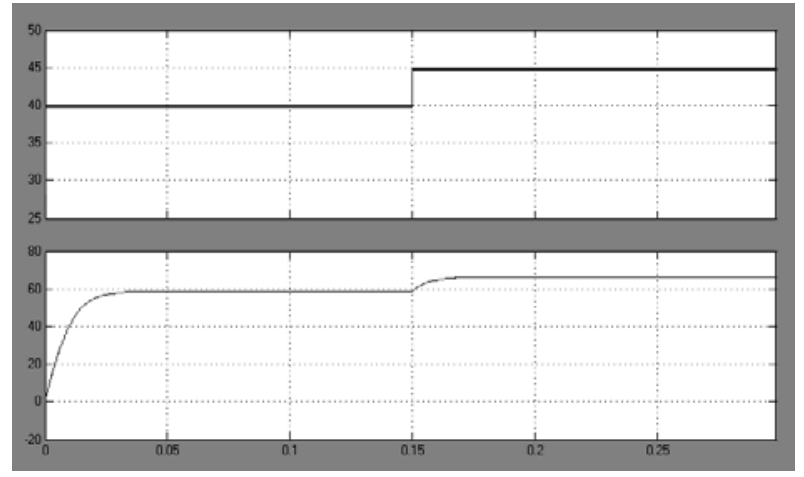

$3 b$ - Input and output voltage with disturbance

Open loop system with a disturbance is shown in Fig 3a. A step change in input is applied as shown in Fig 3b. The output voltage also increases. Output voltage and current are shown in Fig 3c. Closed loop system is shown in Fig 4a. Input voltage with disturbance is shown in Fig 4b.The output voltage and current are shown in Fig 4c.

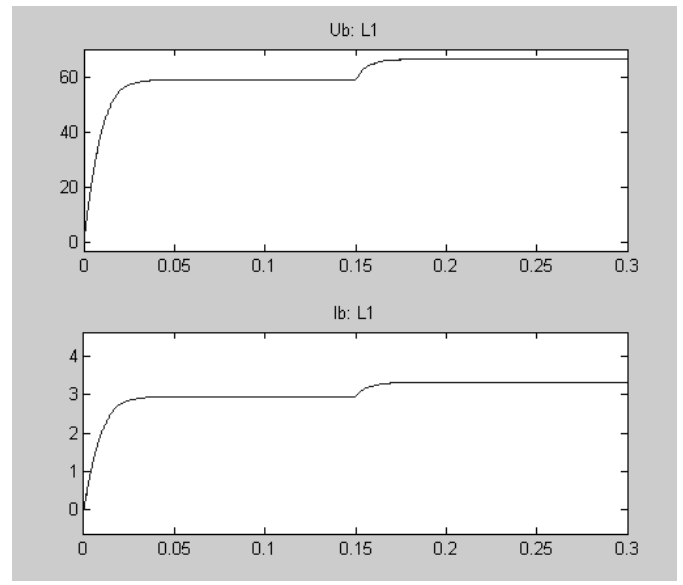

$3 c$ - Output voltage and current with disturbance

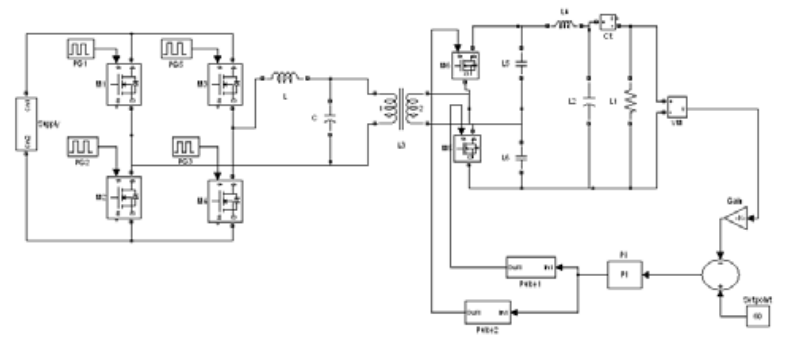

4a - Closed loop Circuit diagram

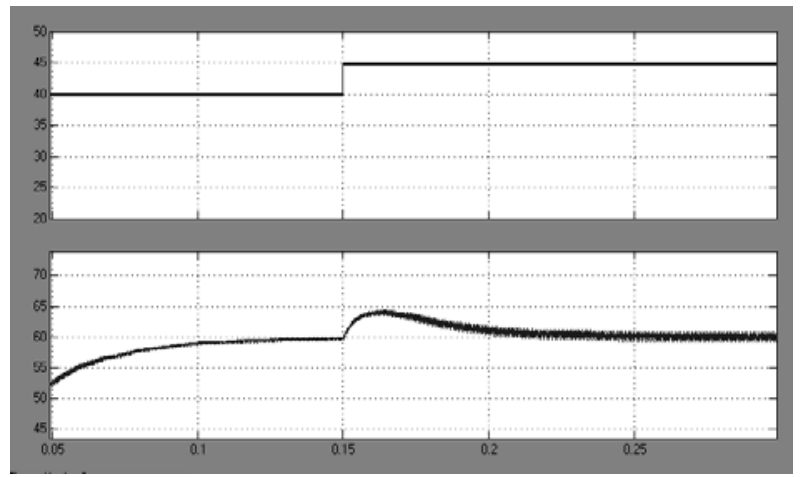

$4 b$ - Input and output voltage with disturbance

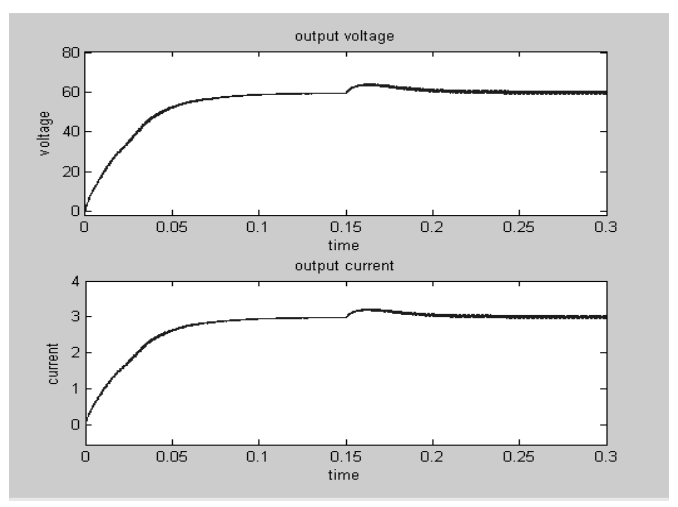

$4 c$ - Output voltage and current with disturbance

\section{EXPERIMENTAL RESULTS}

The hardware is fabricated and tested in the laboratory with resistive load. Pulses required by the MOSFETs are generated by using a microcontroller. These pulses are amplified by using a driver amplifier. Experimental setup is shown in Fig. 5a. AC input voltage is shown in Fig. 5b. Driving pulses are shown in Fig. 5c. Inverter output without filter is shown in Fig. 5 d. Inverter output with filter is shown in Fig. 5e. DC output voltage is shown in Fig. 5f. From the Figs. $2 d$ and $5 f$, it can be seen that the experimental results coincide with the simulation results.

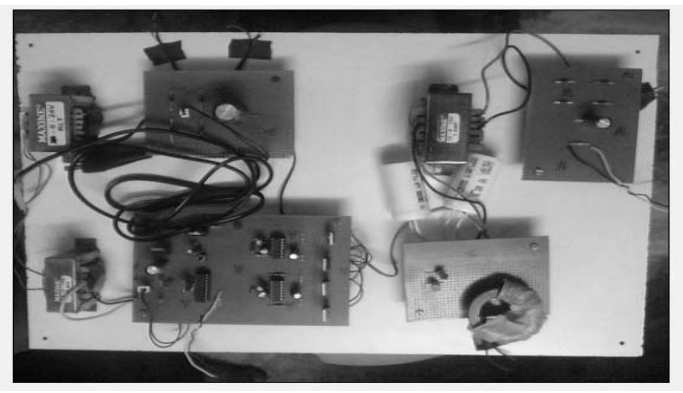

Fig. 5a Experimental Setup 


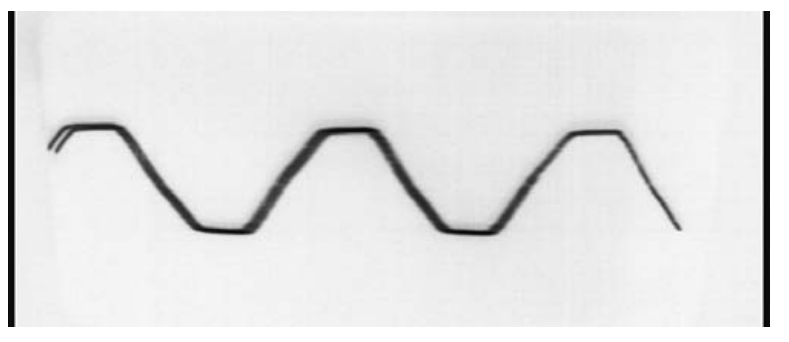

Fig. 5b - AC input voltage

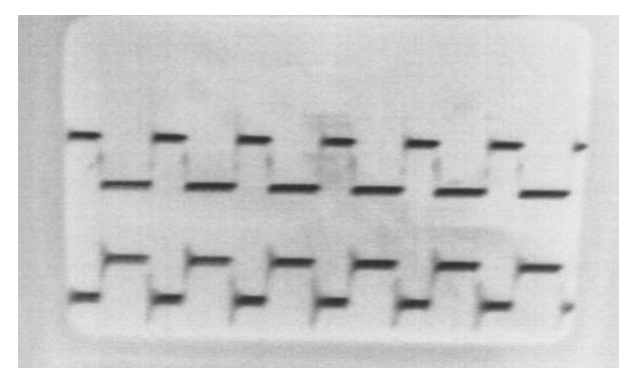

Fig. 5c - Driving pulses

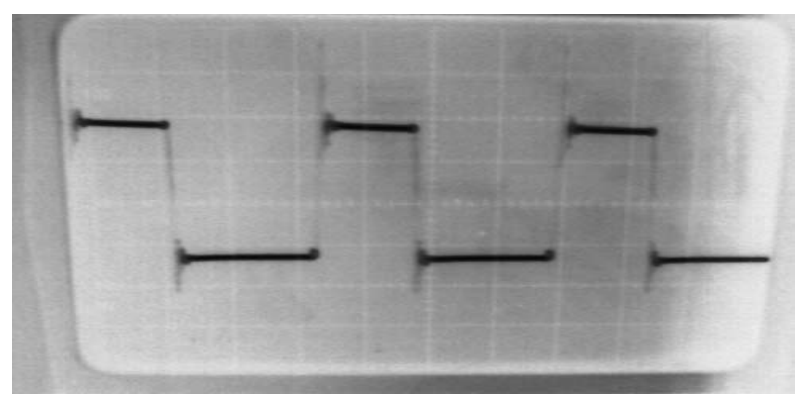

Fig. 5d - Inverter output voltage

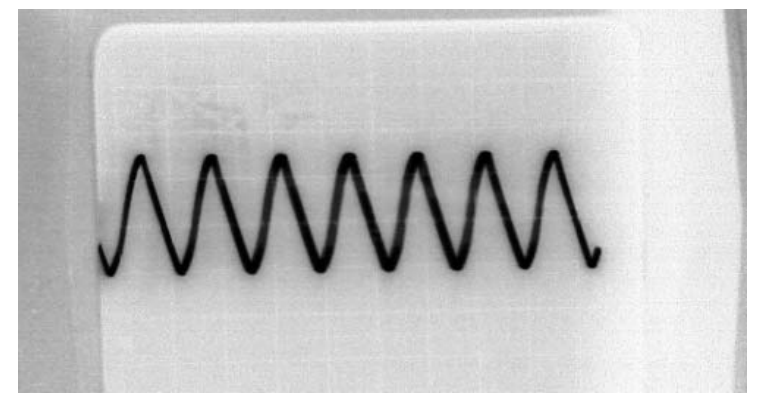

Fig. 5e - Output after LC filter

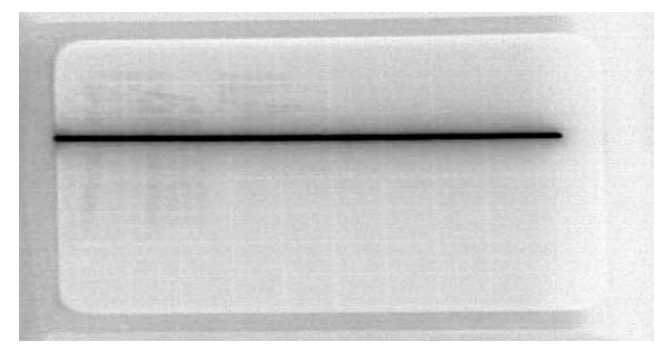

Fig. 5f - DC Output Voltage

\section{CONCLUSION}

A DC-DC converter for electrolyser plant is simulated and implemented. The model for the closed loop system is developed and it is used for simulation of closed loop system. The steady state error is reduced by tuning the parameters of $\mathrm{PI}$ controller. The DC-DC converter system has advantages like reduced switching losses, reduced stresses and reduced EMI. The experimental results closely agree with the simulation results. This converter has advantages like reduced losses sustaining stresses and reduced EMI.

\section{REFERENCES}

1. R.L. Steigerwald, "High-frequency Resonant transistor DC-DC Converters", IEEE Trans on industrial electronics, vol.31, no2, May 1984, pp.181-191.

2. R.L. Steigerwald, "A comparison of half-Bridge Resonant converter topologies", IEEE Trans on Power electronics, vol. 3, no 2, April 1988, pp.174-182.

3. J.A.Sabate \& F.C.Lee,"Off-line application of the fixed-frequency clamped-mode series resonant converter", IEEE Trans on Power electronics, vol. 1, no1, January 1991, pp 39-47.

4. F.S.Tsai, J.Sabate \& F.C Lee, "Constant-frequency, zero voltage-switched, frequency clamped-mode parallel resonant converter", IEEE International Energy conference, 1989, paper\#16.4, pp1-7.

5. A.K.S. Bhat, "Fixed frequency PWM series -parallel resonant converter", IEEE Industry Applications society annual meeting, vol.1, October 1989, pp.1115-1121.

6. A.K.S. Bhat, "Analysis and design of a fixed-frequency LCL-type series resonant converter with capacitive output filter", IEEE Proceedings: Circuits, Devices and systems, vol.144, no2, April 1997, pp.97-103.

7. A.K.S. Bhat, "Analysis \& design of LCL-type resonant converter", IEEE Trans on industrial electronics, vol. 41, no1, Feb 1994, pp.118-124.

8. A.K.S. Bhat, "Analysis \& design of a fixed-frequency LCL-type series resonant converter",IEEE Trans on Aerospace and Electronic systems, vol.31, no1, January 1995, pp 125-137.

9. A.K.S. Bhat \& Fluo, "A new gating scheme controlled soft-switching DC-DC bridge converter", IEEE Power Electronics and drive systems conference record, 2003p 8-15

10. V.Nguyen, J.Dhayanchand \& P.Thollot, "A multiphase topology series-resonant DC-DC converter", in Proceedings of power conversion international, 1985, pp 45-53. 